\title{
HUBUNGAN PENGETAHUAN TENTANG PENDIDIKAN SEKS DENGAN PERILAKU SEKSUAL REMAJA
}

\author{
Afifatul Muarifah ${ }^{1}$, Tritjahjo Danny Soesilo ${ }^{2}$, Umbu Tagela $^{3}$ \\ 1,2,3 Universitas Kristen Satya Wacana \\ Jawa Tengah, Indonesia \\ email : 132015024@student.uksw.edu
}

\begin{abstract}
ABSTRAK
Penelitian dilaksanakan di SMK N 1 Pringapus. Subjek dalam penelitian ini adalah kelas $X$ TSM SMK N 1 Pringapus. Teknik analisis data yang digunakan adalah Kendall's tau. Teknik pengambilan sampel menggunakan teknik total sampling. Pengambilan sampel menggunakan sampel total seluruh siswa kelas XI Tata Busana SMK Negeri 1 Pringapus yang berjumlah 116 siswa. Pengumpulan data menggunakan dua jenis skala, yaitu skala, pengetahuan tentang pendidikan seks dan perilaku seksual yang dikembangkan oleh peneliti berdasarkan teori dari Rahman dan Fachrudin (2000), dan penulis mengadopsi dari Febrian Firza (2011) serta teori Arum dalam Octaviani (2009) dan penulis mengadopsi dari Febrian Firza (2011). Pengolahan datanya menggunakan progam SPSS for Windows 17.0 version. Hasil penelitian menunjukkan bahwa ada hubungan pengetahuan tentang pendidikan seks dengan perilaku seksual remaja siswa kelas XI Tata Busana SMK Negeri 1 Pringapus tahun pelajaran 2018/2019, dengan nilai $r=0,435$ dan koefesien signifikansi $0,000 \leq 0,05$. Maka hubungan kedua variabel tersebut positif dan signifikan. Dengan demikian, hipotesis peneliti "Ada Hubungan Signifikan Antara Pengetahuan Tentang Pendidikan Seks Dengan Perilaku Seksual Remaja Siswa Kelas XI Tata Busana SMK Negeri 1 Pringapus Tahun Ajaran 2018/2019", jadi dapat dikatakan hipotesis diterima.
\end{abstract}

Kata kunci: Pengetahun Tentang Pendidikan Seks, Perilaku Seksual

\section{ABSTRACT}

The research was conducted at Pringapus 1 nd Vocational School. The subjects in this study were class X TSM SMK N 1 Pringapus. The data analysis technique used is Kendall's know. The sampling technique uses total sampling technique. Sampling uses a total sample of all students of class XI Fashion Design at SMK Negeri 1 Pringapus totaling 116 students. Data collection uses two types of scale, namely scale, knowledge about sex education and sexual behavior developed by researchers based on the theory of Rahman and Fachrudin (2000), and adopting authors from Febrian Firza (2011) and Arum's theory in Octaviani (2009) and authors adopted from Febrian Firza (2011). Processing the data using the SPSS program for Windows 17.0 version. The results showed that there was a relationship between knowledge about sex education and the sexual behavior of adolescents in class XI Fashion Design of SMK Negeri 1 Pringapus 2018/2019 school year, with a value of $r=0.435$ and a significance coefficient of $0,00050.05$. Then the relationship between the two variables is positive and significant. Thus, the hypothesis of the researcher "There is a Significant Relationship Between Knowledge About Sex Education with Adolescent Sexual Behavior of Class XI Students of Fashion Vocational School 1 Pringapus Academic Year 2018/2019", so it can be said the hypothesis is accepted

Keywords: Knowledge of Sex Education, Sexual Behavior 


\section{Pendahuluan}

Saat ini bangsa indonesia telah menyadari pentingnya mengutamakan pendidikan, salah satunya adalah pendidikan seks. Pendidikan seks bukan berarti membatasi pergaulan mereka terhadap sesama teman, namun bertujuan agar mereka lebih berhati-hati dalam bergaul. Berkaitan dengan pendidikan seks dan perilaku seksual perlu diadakan survei mengenai hubungan pendidikan seks dan perilaku seksual pada remaja, dipilihnya sampel remaja karena mereka tergolong dalam masa pubertas yang rawan terjebak dalam pergaulan bebas dan sedang dalam pencarian identitas diri yang ditandai dengan keinginan kuat untuk mencoba sesuatu yang baru dalam hidupnya.

Pendidikan seks selama ini dipersepsikan sebagai suatu hal yang tabu dan sifatnya pornografi yang tidak boleh dibicarakan, dibahas apalagi oleh remaja. Masih sedikit pihak yang mengerti dan memahami betapa pentingnya pendidikan seks bagi remaja. Faktor kuat yang membuat pendidikan seks sulit diberikan kepada siswa secara formal ataupun informal adalah pemikiran masyarakat yang belum bisa terbuka dan belum mengetahui pentingnya pendidikan seks bagi remaja.

Menurut Rahman \& Fachrudin (2000) pendidikan seks adalah "perlakuan proses sadar dan sistematis yang dilakukan oleh pihak sekolah, keluarga dan masyarakat untuk menyampaikan informasi seksualitas yang mencakup ruang lingkup seperti perkembangan anak laki-laki dan perempuan, kemampuan personal, perilaku seksual, perilaku sosial, kesehatan seksual, peran keluarga, sekolah, masyarakat dan pemerintah serta problema dan tantangan dalam perkembangannya".

Menurut Sarwono (2002) mengatakan perilaku seksual adalah "segala tingkah laku yang didororng oleh hasrat seksual baik dengan lawan jenisnya". Bentuk-bentuk tingkah laku ini bisa bermacam-macam, mulai dari perasaan tertarik sampai tingkah laku berkencan, bercumbu, dan bersenggama. Dan objek seksualnya bisa berupa orang lain (pasangan).

Cole dalam Octaviani (2009) mengungkapkan bahwa perilaku seksual pada remaja adalah "suatu perkembangan pada remaja yang dipengaruhi oleh kemasakan hormonal, salah satu tanda yang muncul pada fase ini adalah dalam kegiatannnya remaja selalu berusaha membentuk kelompok dengan teman sebaya yang berlainan jenis".

Hasil penelitian yang dilakukan oleh Esti Widiani (2017) di SMA Kristen Setia Budi Malang dengan mengambil sampel sebanyak 58 siswa, didapatkan hasil bahwa sebagian besar responden pengetahuan seks yang tergolong baik dengan hasil 94,83\%, sedangkan untuk perilaku seksual mendapatkan hasil 58,62\%. Hasil uji spearman Rank didapatkan hasil nilai sig (2-tailed) sebesar 0,000<0,05 yang artinya ada hubungan yang signifikan antara tingkat pengetahuan seks dengan perilaku seksual. Sedangkan menurut Fitriani (2011) dari hasil uji chisquare test diperoleh responden dengan pendidikan baik mendapat hasil $88,3 \%$ pendidikan kurang $11,7 \%$ dan perilaku positif sebesar $48,7 \%$ sedangkan perilaku negatif $51,6 \%$. Dari hasil uji statistik hubungan pendidikan seks dengan perilaku seks diperoleh nilai $\mathrm{p}=0,340$ atau tidak ada hubungan yang signifikan antara pendidikn seks dengan perilaku seksual.

Berdasarkan hasil wawancara dengan guru BK diperoleh informasi bahwa sebagian besar siswa kelas XI Tata Busana SMK Negeri 1 Pringapus dalam kaitannya dengan perilaku seksual sering terlihat siswa-siswi berduaan di lingkungan sekolah yang sepi, sambil bermesraan. Masalah tersebut disebabkan salah satunya karena kurangnya pengetauan tentang pendidikan seks.

Sehubungan dengan uraian latar belakang di atas maka penulis tertarik untuk mengadakan penelitian dengan judul "Hubungan pengetahuan tentang pendidikan seks dan perilaku seksual remaja siswa kelas XI SMK Negeri 1 Pringapus. Paat (1998) dalam Gunarsa (2005) mengatakan bahwa dalam pendidikan seks tidak cukup hanya melihat dan mendengar sekali-dua kali, tapi harus dilakukan secara bertahap dan berkelanjutan, sebab pendidikan seks menjadi bagian penting dalam pendidikan di sekolah. Orang tua ikut berperan dalm hal ini, orang tua yang seharusnya pertama-tama memberikan pengetahuan seks bagi anak-anaknya. 
Informasi seks dari, teman, film, buku yang hanya setengah-setengah tanpa pengarah mudah menjerumuskan apalagi si anak tidak tahu resikonya.

Menurut Dianawati (2003) Pendidikan seks merupakan membimbing dan menjelaskan tentang perubahan fungsi organ seksual sebagai tahapan yang harus dilalui dalam kehidupan manusia. Pendidikan seks dapat membantu para remaja laki-laki dan perempuan untuk mengetahui resiko dari sikap seksual mereka dan mengajarkan pengambilan keputusan seksualnya secara dewasa, sehingga tidak menimbulkan hal-hal yang merugikan diri sendiri maupun orang tuanya. Selanjutnya dikatakan memberikan pendidikan seks pada remaja maksudnya membimbing dan menjelaskan tentang perubahan fungsi organ seksual sebagai tahapan yang harus dilalui dalam kehidupan manusia.

Mengingat rasa ingin tahu remaja terutama siswa yang begitu besar, pendidikan seks yang diberikan harus sesuai kebutuhan siswa, serta tidak menyimpang dari prinsip-prinsip pendidikan seks itu sendiri, maka pendidikan seks harus mempertimbangkan; pertama, pendidikan seks harus berdasarkan penghormatan hak reproduksi dan hak seksual remaja untuk mempunyai pilihan. Kedua, berdasarkan pada kesetaraan jender. Ketiga, partisipasi remaja secara penuh dalam proses perencanaan. Keempat, bukan cuma dilakukan secara formal, tetapi juga non formal (Boyke, 2006).

Menurut Rahman dan Fachrudin (2000) mengungkapkan beberapa aspek-aspek pendidikan seks yang perlu diterapkan kepada anak, antara lain: (1) Harapan Orang Tua, Menerapkan pendidikan seks dalam konsep pengenalan seks yang jelas pada anak perlu dan penting, seperti menjelaskan hubungan seks itu apa?, menjelaskan tentang alat kelamin itu apa? menerapkan kepada anak bahwa baiknya hubungan seks dilakukan setelah menikah, kenapa manusia dapat dilahirkan, perilaku menyimpang kejahatan seks dan membimbing anak pada saat menonton acara televisi yang berkategori dewasa, (2) Harapan Sekolah, Terintegrasi pendidikan seks yang diberikan dalam mata pelajaran; agama, olah raga, biologi, sosiolagi, antropologi dan bimbingan konseling. Pendidikan seks yang diberikan tersebut meliputi informasi seksualitas mencakup masalah reproduksi, seksualitas/ seks (jenis kelamin), menjelaskan hubungan seks, menjelaskan tentang alat kelamin, perilaku menyimpang, kejahatan seks, dan perlindungan hukum mengenai seks. Pendidikan seks dalam kegiatan OSIS mencakup dalam program keputrian dan keputraan (Pramuka), Pesantren kilat, Retret. Kemudian pendidikan seks dalam kegiatan POMG (persatuan orangtua murid dan guru) dalam bentuk seminar dan diskusi, (3) Harapan Masyarakat Sekitar, Pendidikan seks yang diberikan masyarakat sekitar adalah bagaimana lingkungan masyarakat berdampak positif atau negatif dalam pemberian informasi seksualitas, pembentukan perkembangan seksualitas pada anak, kegiatan LSM seperti memberikan informasi seks yang tepat atau tidak?, pengenalan mengenai seksualitas, buku porno, film blue dampak negatif dari itu semua.

Perilaku Seksual

Menurut Sarwono (2002) perilaku seksual adalah "segala tingkah laku yang didororng oleh hasrat seksual baik dengan lawan jenisnya. Bentuk-bentuk tingkah laku ini bisa bermacam-macam, mulai dari perasaan tertarik sampai tingkah laku berkencan, bercumbu, dan bersenggama. Dan objek seksualnya bisa berupa orang lain (pasangan)".

Cole dalam Octaviani (2009) mengungkapkan bahwa perilaku seksual pada remaja adalah suatu perkembangan pada remaja yang dipengaruhi oleh kemasakan hormonal, salah satu tanda yang muncul pada fase ini adalah dalam kegiatannnya remaja selalu berusaha membentuk kelompok dengan teman sebaya yang berlainan jenis.

Aspek-aspek perilaku seksual menurut Arum dalam Octaviani (2009) adalah "segala aktifitas yang terkait dengan pemenuhan dorongan seksual dengan lawan jenis aktifitas tersebut dapat diuraiakan sebagai berikut": (a) Berpegangan tangan, (b) Berpelukan, (c). Berciuman,meraba bagian yang sensitif, (d). Melakukan hubungan seksual.

Hubungan Pengetahuan Pendidikan Seks dengan Perilaku Seksual

Remaja dianggap sebagai periode transisi antara masa anak-anak ke masa dewasa atau masa usia belasan tahun yang menunjukan tingkah laku tertentu seperti susah diatur, rasa 
ingin tahu yang tinggi termasuk ingin mencoba tindakan-tindakan yang dilakukan oleh orang dewasa. Salah satu tindakan yang ditirukan oleh remaja adalah mengenai perilaku seksualitas atau hubungan dengan lawan jenis. Remaja bisa saja meniru perilaku orang dewasa yang seharusnya belum waktunya untuk dilakukan diusia remaja. Perilaku menyimpang yang dilakukan oleh remaja dimulai dari perkumpulan dengan teman temannya sampai menonton gambar ataupun film porno. Hal itu dikarenakan kurangnya pengatahuan pendidikan seksual yang diberikan kepada remaja pendidikan yang bersifat formal maupun informal.

Pengetahuan Pendidikan seks selama ini masih dianggap pembicaraan yang tabu di kalangan masyarakat indonesia. Akibat ketidak terbukaan mengenai pendidikan seks, banyak remaja yang malah terjerumus dalam masalah seksualitas. Remaja tidak mengetahui dampakdampak dan juga akibat dari hubungan seks karena kurangnya pendidikan seks yang diterima.

Seiring berkembangnya tehknologi, akses mendapatkan informasi mengenai pendidikan seks sangatlah mudah didapatkan. Remaja yang penasaran maka akan mencari tahu melalui internet tanpa ada penyaringan terlebih dahulu. Terlebih jika remaja semakin erat dengan gadgetnya, maka kesempatan untuk membuka konten-konten pornografi akan semakin mudah tanpa sepengetahuan orangtua.

Pendidikan seks ini perlu diberikan kepada remaja agar remaja tidak terjerumus dalam permasalahan seksual dan perilaku menyimpang, pemberian pengetahuan tentang pendidikan seks tidak hanya diberikan oleh sekolah namun orangtua dan lingkungan masyarakat perlu memberikan bimbingan terhadap remaja.

\section{Metode}

Jenis penelitian ini merupakan penelitian korelasional. Menurut Arikunto (1998), penelitian korelasional yaitu untuk mengetahui ada atau tidak adanya hubungan antara dua atau beberapa variabel. Penelitian ini menghubungkan antara variabel pendidikan seks dan variabel perilaku seksual. Populasi dalam penelitian ini adalah seluruh siswa kelas XI BUSANA BUTIK SMK Negeri 1 Pringapus yang berjumlah 116 orang.

Menurut Sugiyono (2014), sampel adalah bagian dari jumlah dan karakteristik yang dimiliki oleh populasi, dan teknik sampling adalah merupakan teknik pengambilan sampel untuk menentukan sampel dalam penelitian. Teknik pengambilan sampel yang digunakan pada penelitian ini adalah teknik Total Sampling. Yang menjadi sampel dalam penelitian ini adalah siswa kelas XI BUSANA BUTIK SMK Negeri 1 Pringapus yang berjumlah 116 orang.

Uji Validitas

Koefisien validitas item (Corrected Item-Total Corelation) ditentukan valid jika koefesien kerelasi sama atau di atas $\geq 0,30$. Berdasarkan hasil uji validitas item variabel pendidikan seks terdapat 40 item (keseluruhan) tergolong valid dengan rentang koefisien korelasi 0,341 - 0,588. Sedangkan hasil uji validitas item variabel perilaku seksual terdapat 40 item (keseluruhan) tergolong valid dengan rentang korelasi 0,306 - 0,560. Dengan demikian item variabel pendidikan seks dengan perilaku seksual dinyatakan valid karena koefisien korelasi di atas $\geq$ 0,30

Uji Reliabilitas

Reliabitas adalah sejauh mana hasil dari suatu pengukuran dapat dipercaya. Tolak ukur reliabilitas yang dipakai didasarkan pada interpretasi nilai alpha menurut George \& Mallery (1995) sebagai berikut.

Tabel 1. Interpretasi nilai alpha menurut George \& Mallery

\begin{tabular}{cc}
\hline Besar Nilai & Kualifikasi \\
\hline$\frac{0.90}{\underline{0.80}}$ & $\frac{\text { Sangat bagus }}{\text { Bagus }}$ \\
$\underline{0.70}$ & Dapat diterima
\end{tabular}




$$
\begin{aligned}
& \underline{0.60} \\
& \underline{0.50} \\
& \underline{0.40}
\end{aligned}
$$

\section{Meragukan \\ Buruk \\ Tidak dapat diterima}

Pengujian reliabilitas dilakukan dengan cara menguji coba instrument dan dianalisis dengan metode Alpha-Croncbach. Adapun hasil uji reliabilitas adalah sebagai berikut:

Tabel 2. Reliabilitas Pengetahuan Pendidikan Seks

\begin{tabular}{ccc}
\hline & Reliability Statistics & \\
\hline Cronbach's Alpha & $\begin{array}{c}\text { Cronbach's Alpha Based on } \\
\text { Standardized Items }\end{array}$ & N of Items \\
\hline .933 & .933 & 40 \\
\hline
\end{tabular}

Dari uji reliabilitas 40 item pernyataan dalam skala pengetahuan pendidikan seks maka diperoleh angka koefisien Alpha = 0,933 dan berada pada kategori reliabilitas sangat bagus.

Tabel 3. Reliabilitas Perilaku Seksual

\begin{tabular}{ccc}
\hline \multicolumn{3}{c}{ Reliability Statistics } \\
\hline Cronbach's Alpha & $\begin{array}{c}\text { Cronbach's Alpha Based on } \\
\text { Standardized Items }\end{array}$ & N of Items \\
\hline .909 & .910 & 40 \\
\hline
\end{tabular}

Dari uji reliabilitas 40 item pernyaaan dalam kuesiner perilaku seksual maka dapat diperoleh angka koefisien Alpha $=0,909$ sehingga berada pada kategori reliabilitas sangat bagus.

\section{Hasil Dan Pembahasan}

Penelitian ini dilakukan di SMK Negeri 1 Pringapus yang berlokasi di Desa Jatirunggo, Kecamatan Pringapus. Kabupaten Semarang. Kode pos 50553. Subjek pada penelitian ini adalah siswa kelas XI Tata Busana SMK Negeri 1 Pringapus yang berjumlah 116 siswa. Rincian data subjek penelitian dapat dilihat sebagai berikut :

Tabel 4. Data Jumlah Siswa Kelas XI Tata Busana SMK Negeri 1 Pringapus

\begin{tabular}{ccccc}
\hline No & Kelas & Laki-Laki & Perempuan & Jumlah \\
\hline 1 & XI TB 1 & 5 & 24 & 29 \\
2 & XI TB 2 & 6 & 23 & 29 \\
3 & XI TB 3 & 5 & 25 & 30 \\
4 & XI TB 4 & 6 & 22 & 28 \\
& Total & $\mathbf{2 2}$ & $\mathbf{9 4}$ & $\mathbf{1 1 6}$ \\
\hline
\end{tabular}

Data yang diperoleh dalam penelitian ini merupakan hasil analisis dari skala pengetahuan pendidikan seks dan skala perilaku seksual. Skala ini digunakan untuk mengetahui tingkat pengetahuan pendidikan seks dengan perilaku seksual yang ada di siswa kelas XI Tata Busana SMK Negeri 1 Pringapus. Peneliti mengkatagorikan subjek penelitian menjadi empat, yaitu sangat sesuai, sesuai, tidak sesuai, sangat tidak sesuai. 


$$
\text { Interval }=\frac{\text { Jumlah skor tertinggi }- \text { jumlah skor terendah }}{\text { Jumlah kategori }}
$$

Tabel 5. Distribusi Frekuensi Pendidikan Seks

\begin{tabular}{cccc}
\hline Kategori & Interval & Frekuensi & Presentase (\%) \\
\hline Sangat tinggi & $136-160$ & 7 & $6 \%$ \\
Tinggi & $112-135$ & 44 & $38 \%$ \\
Sedang & $88-111$ & 52 & $45 \%$ \\
Rendah & $64-87$ & 12 & $10,2 \%$ \\
Sangat rendah & $40-63$ & 1 & $0,8 \%$ \\
Total & 116 & $100 \%$ & \\
Min & & 60 & \\
Max & & 145 & \\
Mean & & 108.37 & \\
\hline
\end{tabular}

Berdasarkan Tabel 5, Distribusi Frekuensi diatas dapat diketahui bahwa pengetahuan pendidikan seks siswa kelas XI Tata Busana SMK Negeri 1 Pringapus sebagian besar berada pada kategori sedang dengan presentase $45 \%$.

\begin{tabular}{|c|c|c|c|c|}
\hline \multirow[b]{2}{*}{$\begin{array}{l}\text { Kendall's } \\
\text { tau_b }\end{array}$} & \multirow[b]{2}{*}{ Pendidikan Seks } & \multirow[b]{2}{*}{$\begin{array}{l}\text { Correlation } \\
\text { Coefficient }\end{array}$} & Pendidikan Seks & Perilaku Seksual \\
\hline & & & 1.000 & $.435^{\star *}$ \\
\hline & & Sig. (2-tailed) & . & .000 \\
\hline & & $\mathrm{N}$ & & 116 \\
\hline & Perilaku Seksual & $\begin{array}{l}\text { Correlation } \\
\text { Coefficient }\end{array}$ & $\begin{array}{l}116 \\
.435^{* *}\end{array}$ & 1.000 \\
\hline & & Sig. (2-tailed) & .000 & . \\
\hline & & $\mathrm{N}$ & 116 & 116 \\
\hline
\end{tabular}

Tabel. 6. Correlations

**. Correlation is significant at the 0.01 level (2-tailed).

Berdasarkan hasil uji korelasi diatas maka diketahui nilai $r=0,435$ dengan koefesien signifikansi $0,000 \leq 0,05$. Dengan demikian dapat ditarik kesimpulan bahwa ada hubungan signifikan antara Pengetahuan Pendidikan Seks dengan Perilaku Seksual siswa kelas XI Tata Busana SMK Negeri 1 Pringapus.

Dari hasil koefisien korelasi pada pengujian hipotesis, diketahui koefisien korelasi 0,435. dan dilihat dari tabel menunjukkan tingkat interval korelasi yaitu antara 0,40-0,599, jadi dapat diartikan koefisien korelasi memiliki tingkat hubungan sedang atau rata-rata.

Dari hasil uji hipotesis yang dilakukan, menunjukkan bahwa ada hubungan signifikan antara pengetahuan pendidikan seks dengan perilaku seksual siswa kelas XI Tata Busana SMK Negeri 1 Pringapus, dengan hasil koefisien korelasi antara pengetahuan pendidikan seks dengan perilaku seksual dengan nilai $r=0,435$ dan koefesien signifikansi $0,000 \leq 0,05$. Dengan demikian hipotesis diterima dan berbunyi ada hubungan yang signifikan antara pengetahuan pendidikan seks dengan perilaku seksual siswa kelas XI Tata Busana SMK Negeri 1 Pringapus. 
Hasil penelitian ini mendukung dari hasil penelitian yang dilakukan oleh Esti Widiani (2017) di SMA Kristen Setia Budi Malang dengan mengambil sampel sebanyak 58 siswa, didapatkan hasil bahwa sebagian besar responden pengetahuan seks yang tergolong baik dengan hasil 94,83\%. Sedangkan untuk perilaku seksual mendapatkan hasil 58,62\%. Hasil uji Kendall's tau didapatkan hasil nilai sig (2-tailed) sebesar 0,000<0,05 yang artinya ada hubungan yang signifikan antara tingkat pengetahuan pendidikan seks dengan perilaku seksual.

Dapat dilihat juga berdasarkan deskripsi data tabel kategorisasi pada variabel pendidikan seks, dilihat dari tabel distribusi frekuensi, tingkat pengetahuan pendidikan seks siswa kelas XI Tata Busana SMK Negeri 1 Pringapus, yang memilki kategori sangat rendah $0,8 \%$, kategoti rendah $12,2 \%$, kategori sedang $45 \%$, kategori tinggi 38\%, dan pada kategori sangat tinggi $6 \%$. Hal ini menunjukkan bahwa siswa kelas XI Tata Busana SMK Negeri 1 Pringapus tergolong memiliki pengetahuan pendidikan seks rata-rata. Hal ini dapat diartikan bahwa siswa kelas XI Tata Busana SMK Negeri 1 Pringapus memiliki pendidikan seks sedang.

Pada variabel perilaku seksual, dilihat dari tabel distribusi frekuensi, tingkat pendidikan seks siswa kelas XI Tata Busana SMK Negeri 1 Pringapus, yang memilki kategori sangat rendah $0 \%$, kategoti rendah $12,2 \%$, kategori sedang $42,2 \%$, kategori tinggi $36,2 \%$, dan pada kategori sangat tinggi 9,4\%. Hal ini menunjukkan bahwa siswa kelas XI Tata Busana SMK Negeri 1 Pringapus tergolong memiliki perilaku seksual sedang atau rata-rata. Hal ini dapat diartikan bahwa siswa kelas XI Tata Busana SMK Negeri 1 Pringapus memiliki perilaku seksual yang baik.

\section{Simpulan dan Saran}

Berdasarkan hasil penelitian dapat disimpulkan bahwa ada hubungan yang signifikan antara pendidikan seks dengan perilaku seksual siswa siswa kelas XI Tata Busana SMK Negeri 1 Pringapus dengan nilai $r=0,435$ dan koefesien signifikansi 0,000 0,05.

Setelah melakukan penelitian dan mengkaji hasil dari penelitian, maka penulis memiliki beberapa saran yaitu : (a) Bagi Siswa, Untuk siswa-siswi diharapkan agar dapat meningkatkan pengetahuan tentang pengetahuan pendidikan seks yang benar, sehingga siswa lebih mampu mengantisipasi perilaku seksual yang tidak baik dan dapat merugikan diri sendiri maupun kehidupan bermasyarakat. Untuk meningkatkan pengetahuan pendidikan seks yang baik dapat dilakukan dengan menanyakan kepada orang tua, masyarakat sekitar dan kepada guru di sekolah, (b) Bagi Pihak sekolah, Bagi pihak sekolah terutama guru bimbingan dan konseling diharapkan dapat memberikan pengetahuan pendidikan seks dan perilaku seksual dengan baik, untuk memberikan informasi guru dapat bekerjasama dengan instansi terkait untuk memberikan penyuluhan kepada siswa agar siswa mendapat informasi yang benar mengenai seksualitas agar siswa dapat mengantisipasi perilaku seksual yang tidak sehat.

\section{Daftar Rujukan}

Ali, Mohamad. 1984. Penelitian Kependidikan Prosedur dan Strategi. Bandung: Angkasa.

Arikunto, S. 2010. Prosedur Penelitian Suatu Pendekatan Praktik. Jakarta: Rineka Cipta.

Azwar, S. 2003. Penyusunan Skala Psikologi Cet12. Yogyakarta: Pustaka Pelalajar.

Azwar, S. 2009. Reliabbilitas dan Validitas. Yogyakarta: Pustaka Pelajar.

Boyke. (2006). Pendidikan Seks Lebih Penting Untuk Mengatasi Dampak Pornografi Daripada Sebuah Undang-Undang: Kompas hal. 11. 
Budi Widiyanto, Purnomo, Arum Muria Sari. 2013. Pengaruh Pemberian Pendidikan Kesehatan Reproduksi Remaja Terhadap Pengetahuan Tentang Perilaku Seksual. Jurnal Keperawatan Komunitas. Vol 1, No 22013.

Dariyo, A. (2004). Psikologi Perkembangan Remaja. Bogor: Ghalia Indonesia.

Dianawati, A. (2003). Pendidikan Seks Untuk Remaja. Jakarta: Kawan Pustaka.

Ermina, H. (2005). Hubungan Antara Kecemasan Terhadap Test Dan Prestasi Belajar Siswa Kelas II SMA Negeri 2 Salatiga Semester II Tahun Ajaran 2004/2005. Skripsi. Program Studi Bimbingan dan Konseling FKIP-UKSW Salatiga.

Fauzan, F dkk. (2003). Pendidikan Seks Bagi Remaja. www.ceritaremaja.com. (01/07/06).

Fitriana. 2012. Hubungan Pengetahuan Dan Sikap Tentang Seks Pranikah Dengan Perilaku Seksual Pada Siswa Smk Xx Semarang. Jurnal Komunikasi kesehatan. Vol 3 No 01, 2012.

George \& Mallery. 1995. SPPS/PC, Step by Step: A Simple Guide and Reference.

Balmont: Wadsworth Publishing Companu.

Harni Andriani. 2016. Hubungan Pengetahuan, Akses Media Informasi Dan Peran Keluarga Terhadap Perilaku Seksual Pada Siswa Smk Negeri 1 Kendari Tahun 2016. Jurnal IImiah Mahasiswa Kesehatan Masyarakat. Vol 1, No 32016.

Hurlock, E.B. (1991). Psikologi Perkembangan: Suatu pendekatan Sepanjang Rentang Kehidupan. Jakarta: Erlangga.

Kirkendall, L.A. (1985). Anak dan Masalah Seks. Jakarta: Bulan Bintang.

Mertia. 2011. Hubungan Antara Pengetahuan Seksualitas Dan Kualitas Komunikasi Orangtua Dan Anak Dengan Perilaku Seks Bebas Pada Remaja Siswa-Siswi Man Gondangrejo Karangnyar. Jurnal Psikologi. Vol 3, No 2, 2011.

Naek, W. A. (2006). Pendidikan Seks Harus Tepat. www.bkkbn.com. (25/03/2006).

Raditya. (2002). Urgensi Pendidikan. www.republika.com. (02/07/06).

Rahman, A dan Fachrudin. (2000). Pendidikan Seks di Sekolah. Jakarta: Fasco.

Rahman, A. (2003). Pendidikan Seks. www.funkyhosting.com. (02/07/06).

Sarwono, S. (2000). Psikologi Remaja. Jakarta: P.T. Raja Grafindo Persada.

Sarwono, S. \& Siamsidar, A. (1986). Peran Orang Tua Dalam Pendidikan Seks. Jakarta: CV. Rajawali.

Slameto. (2003). Metodologi Pendidikan. Program Studi Bimbingan Dan Konseling, FIP UKSW Salatiga.

Sugiyono. 2011. Metode Penelitian Kuantitatif, Kualitatif dan R\&D. Bandung : Alfabeta 
Sujarwati, Anafrin Yugistyowati \& Kayat Haryani, 2014. Peran Orang Tua dan Sumber Informasi dalam Pendidikan Seks dengan Perilaku Seksual Remaja pada Masa Pubertas di SMAN 1 Turi. Jurnal Ners dan Kebidanan Indonesia. Vol. 2, No. 3, Tahun 2014, 112-116.

Suryana, Y. (2003). Parafilia Sebagai Deviasi Seksual Dan Pengobatannya. www.indomedia .com $(28 / 03 / 2006)$.

Tetty Rina Aritonang. 2015. Hubungan Pengetahuan Dan Sikap Tentang Kesehatan Reproduksi Dengan Perilaku Seks Pranikah Pada Remaja Usia (15-17 Tahun) Di Smk Yadika 13 Tambun, Bekasi. Jurnal IImiah Widya. Volume 3 Nomor 2 September Desember 2015.

Tukan, J.S. (1994). Metoda Pendidikan Seks, Perkawinan, dan Keluarga. Jakarta: Erlangga. 